\title{
The role of redevelopment in the development of the spatial organization of production
}

\author{
Vitaly Lukinov ${ }^{1, *}$, Alexander Shlafman ${ }^{2}$ and Alexander Zheltenkov ${ }^{3}$ \\ ${ }^{1}$ Moscow State University of Civil Engineering, Yaroslavskoeshosse, 26, Moscow, 129337, Russia \\ ${ }^{2}$ Baltic Academy of tourism and entrepreneurship, Petrozavodskaya str., 13, lit. A, Saint-Petersburg, \\ 191144, Russia \\ ${ }^{3}$ Moscow regional state University, Radio str., 10, Moscow, 129125, Russia
}

\begin{abstract}
Modern enterprises are steadily developing. Development takes place with different speed, but lack of development leads to reduction activities. The company is constantly introducing innovations to keep the pace of development. The development involves the extension activities. The expansion focuses on the physical boundaries of the enterprises. In the future, its development, the company must predict the time when the estate should be expanded. On the other hand, the extension is not always possible within the boundaries of a given territory. So each company goes through a stage of transformation of its location. The change of place of activity related to the transfer of production capacity, we disclose via the category of redevelopment areas. In European practice, proceedings of the technology of redevelopment have a practice for over 30 years. Russian economy is faced with the necessity of solving such problems, only in the new Millennium. Previously planned organization of the economy is clearly shaped conditions for the functioning of industries and given expert guidance on the timing and the postponements of the proceedings. The Russian economy is building new inter-industry relations and problems of implementation of redevelopment programs are in demand. They affect the interests of the state, construction companies and manufacturers directly. The combination of these market participants need to develop organizational solutions that will not hinder the progressive development of the economy of the region and specific production.
\end{abstract}

\section{Introduction}

The transformation of the national economy of Russia is a gradual process of development, which includes a set of agreed spatial changes.

So in most regions arise naturally and consistently resolved the problem of providing areas for the development of certain forms of management, as well as provides the necessary conditions for the development of their infrastructure.

The change in spatial distribution of many economic actors is the focus of the regional economy in the time continuum. While planning these transformations in the regional

\footnotetext{
${ }^{*}$ Corresponding author: prof lukinov@list.ru
} 
economy should be planned and have a clear time frame. The conditions of the planning of a new production location and moving old plants and affects the processes of refunctionalization lands and revision of management practices.

Changing patterns of economic life involves making adjustments in the system control the spatial distribution of production and other objects in the regions containing major Metropolitan area. The regional administration of modern cities, sharing the heritage of the past century with modern society and new citizens, defines the requirements for industrial facilities.

\section{Methods}

Investigating the foreign experience of reforming the economy $[1,2,4,5]$, are observed the positive results of the use of the redevelopment mechanism in the process of transformation of the territorial entities. The most widespread redevelopment (redevelopment) received in the USA during the last 40-50 years. Currently, 49 States and the district of Columbia use approved state laws the Toolkit for implementation of projects of redevelopment. This instrumentation most often used in cases where degradation processes cities becomes obvious and irreversible in this situation. However, the study of the regulatory framework and analytical articles related to the redevelopment, it indicates that insufficient theoreticmethodological basis and rather on the predominance of the legal fixation of existing practices. For example, in California the last 14 years, regularly held conference "Annual Southern California Conference on Redevelopment Abuse", where, in particular, the disclosed abuse in the field of redevelopment. The materials of the conference were given the opportunity to a group of authors to publish an annual report, "Redevelopment: The Unknown Government" (Redevelopment: the Unknown government), which includes criticism of the experience and best practices, but does not consider theoretical and methodological aspects of redevelopment $[2,6,7,8]$.

Under current California law, "California Community Redevelopment Law" the following definition:

"Redevelopment" ("restructuring", "new line") means the planning, development, replanning, modernization, removal, reconstruction, restoration, or any combination of them, in part and in whole, to ensure the compliance of residential, commercial, industrial, public and other facilities in the interests of the General welfare.

On the merits of the law, redevelopment - reconstruction of the spatial organization of production in the region, settlements or individual city blocks, districts, neighborhoods with the use of own and attracted investments. The main purpose of redevelopment - improving the financial autonomy of territories and the formation of their economic independence, indirectly suggesting the solution of social, environmental and institutional problems.

One of the innovative approaches, at least in Russian practice is legally considered as redevelopment areas.

Redevelopment is the transformation of material properties, their complexes, as well as specific areas of addressed by a private recovery efficiency, and the re-creation of positive external effects (social, economic, environmental)

Redevelopment is a process of qualitative material transformation and regime change in the functional use of individual properties, groups or complexes of such objects to the current time lost the effectiveness of economic, social, environmental[5,8,9].

Previously discussed specifics of the redevelopment in relation to the property management system, and industrial redevelopment. And in order for you to maximize all aspects of the strategic significance of the redevelopment when viewed from different positions (like process activities, in General, as a tool of the economy), it seems appropriate to consider the preconditions of this phenomenon. 


\section{Results}

The concept of redevelopment is by definition ambiguous, at least in the Russian interpretation, because English is derived from redevelopment. Owing etymological features, and given the close connection with urban redevelopment, management and investment activities within the framework of the stated topic is represented logically justified to start a study of the redevelopment of the disclosure system of real estate management of the city.

Based on the study of foreign practices, there are grounds to argue that one of the effective tools employed by the control system of spatial organization of production areas is redevelopment. We should pay attention to the fact that endowing the redevelopment of the transformation function of the spatial organization of production relations, we are transforming relations between regions in the implementation of barter and supporting operations.

In a General sense, the term redevelopment is derived from the development.

Development - the material transformation of real estate that increases their value and leading, typically, to an increase in aggregate real estate Fund [3, 9].

At its root, redevelopment is a form of "development" that literally means development.

Within the General concept of development as a professional activity in the real estate market can be highlighted the following subtypes:

1. land development (land development)

2. new construction

3. modernization

4. restoration

5. reconception.

Each of the subspecies has the nuances of the implementation process. However, a closer look at it conception.

Appeal to the theory of life cycles of the projects gives an understanding that regardless of the quality originally created the concept, the degree of profitability of this or that object of real estate effective owner (Manager) is faced with the need to adjust or fundamentally change the use case, the functionality of the disposable object. This is the essence of the conception. In English transcription, this direction is defined as the adaptive use, that is, adaptation to the constraints and needs of modern use. And within the limits of this direction distinguish this strategy as redevelopment. Overall - this is a project of major renovation, new construction on the old site.

\section{Discussion}

The key technique, included in the basis of redevelopment, as the business is complete dismantling (deconstruction) or dismantling with some degree of preservation of the previous structures and then new construction.[1,7,10-12]

So, given the conceptual distinction gives reason to the following conclusion for the clearest possible identification of redevelopment should be considered in three dimensions.

First, redevelopment is a kind of professional business activities in the real estate market, based on the development and implementation of a new format of use of the property.

Secondly, the redevelopment of the qualitative material transformation of the property (of a set of objects, a whole district, district), lost to the current period (at the modern stage of the life cycle) market value as a result of the high degree of wear, maintaining its market potential. 
In this case this transformation leads not only to an increase in the value of the object, but also to gain material resources. And, thirdly, which is especially important in the context of the announced topic, redevelopment is a tool to improve the real estate management system of the city. Further in the text as synonyms for the word redevelopment will be used terms: regeneration, renovation, refunctionalisation.

In connection with the need for the most detailed disclosure of the meaning and practical importance of the redevelopment in the following sections of the paper will be given several additional formulations of the term. Regional, urban conversion areas and/or property complexes of the industrial enterprises, implying a change in the functional purpose of the territory and the creation of modern objects of capital construction is one of the most challenging areas. Projects of redevelopment of industrial territories are capitalintensive. In this regard, the implementation of such projects is appropriate in the Central and developed areas of the city where there is a deficit of free for construction territories and the land prices are quite high[10,11,12-18].

A concise introduction to industrial redevelopment represents the following scheme: the isolation of the area (quarter) of a set of objects, lost, an acceptable level of profitability development and substantiation of the project of renovation of the section (object) - the search and the involvement of necessary resources - implementation of the concept - the order results (the distribution of positive and leveling of the negative effects).

A more detailed consideration of the nature of redevelopment as a development project is viable by examining its objectives, structure, and composition of participants, risks, stages. A concise introduction to industrial redevelopment represents the following scheme: the isolation of the area (quarter) of a set of objects, lost, an acceptable level of profitability - development and substantiation of the project of renovation of the section (object) - the search and the involvement of necessary resources - implementation of the concept - the order results (the distribution of positive and leveling of the negative effects).

A more detailed consideration of the nature of redevelopment as a development project is viable by examining its objectives, structure, and composition of participants, risks, stages. Budget transfer of businesses outside the city tens of millions of dollars. The company should pay for the infrastructure and engineering preparation of new sites, to invest in the construction of new buildings and their equipment. You will also need the renewal of the land from the industrial zone in public business, and it is also money. In addition, operating companies may require compensation for loss during the moving of the profits[13].

Another problem is the renovation of the territories are different limits and the need to preserve existing buildings. So, may be monuments under the protection of the Committee on state control, use and protection of monuments of history and culture. Sometimes it is impossible to adapt the space to modern function, creating a comfortable living environment.

\section{Conclusions}

The distribution of the resource potential on the territory of the Federation is extremely uneven, and each region tries to strengthen its positions on the preservation and extension of individual opportunities for its development. The combination of regulatory requirements and use of the resource potential of the region dictate the direction of development of industrial production and the mechanisms of their interaction with the market environment. Every industrial production is not a separate entity, isolated from the support subsystems of the regional economy. Any modern enterprise depends on infrastructure security activities. 
Thus, the development of industrial production in the regional economy must meet a number of requirements, which can be illustrated by the rules or principles for the implementation of production activities.

\section{References}

1. A. McLean, G.W. Eldred,Investing in real estate (2007)

2. R.B. Peiser, Professional real estate development: the ULI Guide to business (Urban Land Institute, Washington, D.C., 2003)

3. I.Yu. Zagoruiko, A.N. Pytkin,Conceptual aspects of the redevelopment of industrial company towns(Publishing house of Institute of Economics, Ekaterinburg,2010)

4. Y.O. Baklunov,Development of the model of activities in investment and construction sphere(2007)

5. An.B. Mottaeva, As.B. Mottaeva, Int. Journal of Applied Engineering Research 10, 1723 (2015)

6. A.B. Mottaeva, A. Zheltenkov, I. Stukanova, S. Ryabichenko, S. Zhuk, MATEC 73, 07026 (2016)

7. I. Polyakova, E.Vasilyeva, Procedia Engineering, 165 (2016)

8. An.B. Mottaeva, As.B. Mottaeva, Int. Journal of Applied Engineering Research, 11- 9 (2016)

9. An.B. Mottaeva, As.B. Mottaeva, Int. Journal of Applied Engineering Research,10- 23 (2015)

10. E. Stein, N. Taskaeva, E.Chibisova, Procedia Engineering 165, 1410-1416 (2016)

11. T. Miroshnikova, N. Taskaeva, MATEC 73, 123284 (2016)

12. A. Pimenova, S. Kuzmina, N. Morozova,A. Mottaeva, MATEC 73, 07018 (2016)

13. A.I. Shlafman,V.M. Korabel'nikov,VestnikINZhJEKONa 32(5), 123-128(2009)

14. E. Stein, N. Taskaeva, E. Chibisova,Procedia Engineering, 165 (2016)

15. T. Miroshnikova, N. Taskaeva, MATEC 73, 07006 (2016)

16. L.V. Nikolova, D.G. Rodionov, A.B. Mottaeva, International Journal of Economics and Financial Issues 6(S3), 1-7 (2016)

17. N.G. Verstina, E.M. Akimova, T.N. Kisel, N.N. Taskaeva, Asian Social Science, 1114 (2015)

18. N.G. Verstina, T.S. Meshcheryakova, Biosciences Biotechnology Research Asia, 12 2 (2015)

19. A.Mottaeva, MATEC 73, 07020 (2016) 